\title{
THE GPS / EGNOS POSITIONING QUALITY IN APV-1 AND LPV-200 FLIGHT PROCEDURES
}

\author{
Grzegorz Grunwald $^{1, *}$, Adam Ciećko ${ }^{1}$, Kamil Krasuski², Rafał Kaźmierczak \\ ${ }^{1}$ Faculty of Geoengineering, University of Warmia and Mazury in Olsztyn, Olsztyn, Poland \\ ${ }^{2}$ Institute of Navigation, Military University of Aviation, Deblin, Poland \\ *E-mail of corresponding author: grzegorz.grunwald@uwm.edu.pl
}

\begin{abstract}
Resume
Accuracy, integrity, continuity and availability are the basic quality parameters extremely important in satellite navigation. The article presents results of research using the European Geostationary Navigation Overlay Service (EGNOS) that belongs to the group of Satellite Based Augmentation Systems (SBAS). The measurement data adopted for analysis were recorded in years: 2012, 2014, 2015, 2017 and 2018 in the north-eastern Poland. Results of the analysis showed a significant reduction in the maximum GPS / EGNOS positioning error values from 2014 onwards (compared to results from 2012). In general, values of parameters characterizing accuracy, integrity and availability meet the requirements for EGNOS applications in APV-1 and LPV-200 aviation procedures. It the case of continuity the requirements are not met.
\end{abstract}

Available online: https://doi.org/10.26552/com.C.2021.2.E23-E34

\section{Article info}

Received 19 March 2020

Accepted 10 August 2020

Online 18 January 2021

\section{Keywords:}

satellite navigation,

SBAS,

EGNOS,

GNSS positioning

\section{Introduction}

The European Geostationary Navigation Overlay Service (EGNOS) is designed to support the operation of Global Navigation Satellite Systems (GNSS), belonging to the SBAS (Satellite Based Augmentation System) group. Currently, it supports the GPS (Global Positioning System) system only, and theoretically GNSS / SBAS positioning should improve the quality of position determination [1-4]. This is associated with use of EGNOS mainly in aviation. Its proper functioning and development have been overseen by the European Union represented by the European Commission, the European Space Agency (ESA) and Eurocontrol (European Organization for the Safety of Air Navigation) since 1994 [5-6].

EGNOS provides its products through three services: OS (Open Service), SoL (Safety of Life), EDAS (EGNOS Data Access Service) and is being gradually modernized [7]. Since the launch of the Safety of Life Service in 2011 [8], there have been 6 new EGNOS versions introduced. The ESR (EGNOS System Release) V2.2 (Initial Entry into Service) was launched in 2011 and the ESR V2.3.1 (software corrections) was commenced in 2012. The ESR V2.3.2 was launched in 2013 in order to improve the EGNOS resistance to influence of the ionosphere effect; however, during the very high ionosphere activity some complications were observed. These deficiencies were corrected in 2015 by the ESR V2.4.1M, which also introduced the LPV-200 operability [9]. The ESR V2.4.1N launched in 2017 was associated with the new geostationary satellite and new uplink stations. In 2018, further modernizations related to the new RIMS (Ranging Integrity Monitoring Station) activation in Haifa $\left(72^{\circ}\right.$ North Lat) and GPS week number rollover, were introduced.

Previous studies on positioning quality using the EGNOS system indicate the possibility of positioning with an accuracy of less than $2 \mathrm{~m}$ [9-13]. However, in air navigation, values of parameters related to integrity, continuity and availability of positioning are also very important.

Motivation of this article is to examine quality of the GPS / EGNOS positioning in the north-eastern Poland, taking into account modifications of the EGNOS system since 2011. This type of analysis gives an overview of the possibilities of application and expectations of the system in applications related, among others, to air transport.

\section{Quality parameters of the GPS / EGNOS positioning}

Quality of the real-time positioning is very important in application of satellite systems in aviation. Four main parameters are the most significant in air applications, i.e. accuracy, integrity, availability and continuity [14-16].

Accuracy of the estimated or measured position, at a given time, is defined as its level of certainty relative to the real position of a receiver at that time [14]. Values of the HPE (Horizontal Position Error) and VPE (Vertical Position 
Error) can be determined based on the following formulas:

$$
\begin{aligned}
H P E_{i} & =\sqrt{\left(B_{i}-B_{R E F}\right)^{2}+\left(L_{i}-L_{R E F}\right)^{2}}, \\
V P E_{i} & =\left|H_{i}-H_{R E F}\right|,
\end{aligned}
$$

where:

$H P E_{i}$ - horizontal position error for a given epoch,

$B_{i}, L_{i}$ - horizontal coordinates determined by the receiver in a topocentric system,

$B_{R E F}, L_{R E F}$ - horizontal reference coordinates in a topocentric system,

$V P E_{i}$ - vertical position error for a given epoch,

$H_{i}$ - ellipsoidal height determined by the receiver for a given epoch,

$H_{R E F}$ - ellipsoidal reference height.

Integrity should be understood as the probability and correctness of information provided by the navigation system [14]. The Horizontal Protection Level (HPL) and Vertical Protection Level (VPL) are closely related to integrity of the real-time positioning $[4,17]$. The Protection Level (PL) in the horizontal plane (HPL) according to RTCA [17] is the radius of the centre circle in the real position, which corresponds to the area containing the position calculated by the system. In contrast, the vertical Protection Level (VPL) is the length of half the cylinder axis with the centre in the true position, which corresponds to the area containing the vertical position calculated by the system.

The HPL and VPL values are influenced by ionosphere and troposphere activity, satellite geometry, ephemeris errors, satellite clock errors and those related to receiver operation

During the research, a model for determining the HPL and VPL values in accordance with RTCA guidelines was used. The PL values are determined by the formulas [17-19]:

$$
\begin{aligned}
& H P L=K_{H} d_{\text {major }}, \\
& V P L=K_{V} \sigma_{U}
\end{aligned}
$$

where:

$K_{H}$ - coefficient limiting the horizontal position with probability $10^{-9}$ (for "en-route" and NPA (Non-Precision Approach) $K_{H}=6.18$; for APV-1 approach (Approach with Vertical Guidance) and LPV-200 (Localizer Performance with Vertical Guidance) $K_{H}=6.0$ ),

$K_{V}$ - coefficient limiting the vertical position with a probability $0.5 \times 10^{-7}\left(K_{V}=5.33\right)$.

$$
\begin{aligned}
d_{\text {major }} & =\sqrt{\frac{d_{E}^{2}+d_{N}^{2}}{2}+\sqrt{\left(\frac{d_{E}^{2}-d_{N}^{2}}{2}\right)^{2}+d_{E N}^{2}}}, \\
d_{E}^{2} & =\sum_{i=1}^{n} S_{E, i}^{2} \sigma_{i}^{2}, d_{N}^{2}=\sum_{i=n}^{n} S_{N, i}^{2} \sigma_{i}^{2}, \\
d_{E N} & =\sum_{i=1}^{n} S_{E, i} S_{N, i} \sigma_{i}^{2}, d_{v}^{2}=\sum_{i=1}^{n} S_{U, i}^{2} \sigma_{i}^{2},
\end{aligned}
$$

$$
S=\left[\begin{array}{llll}
S_{E, 1} & S_{E, 2} & \cdots & S_{E, n} \\
S_{N, 1} & S_{N, 2} & \cdots & S_{N, n} \\
S_{U, 1} & S_{U, 2} & \cdots & S_{U, n} \\
S_{t, 1} & S_{t, 2} & \cdots & S_{t, n}
\end{array}\right],
$$

where:

$\boldsymbol{S}$ - projection matrix

$d_{E}^{2}, d_{N}^{2}, d_{U}^{2}$ - variances of East, North and Up components, expressed in a topocentric system,

$d_{E N}$ - covariance between the East and North axes.

Variance of the pseudo-distance measurement for positioning using the SBAS systems can be determined according to RTCA requirements:

$\sigma_{i}^{2}=\sigma_{i, f l t}^{2}+\sigma_{i, \text { UIRE }}^{2}+\sigma_{i, \text { air }}^{2}+\sigma_{i, \text { tropo }}^{2}$,

where:

$\sigma_{i}^{2}$ - pseudorange measurement variance,

$\sigma_{i, f l t}^{2}$ - variance of fast and long-term corrections,

$\sigma_{i, \text { UIRE }}^{2}$ - variance of ionospheric delay,

$\sigma_{i, a i r}^{2}$ - variance related to the operation of the GNSS receiver,

$\sigma_{i, \text { tropo }}^{2}$ - tropospheric delay variance.

For the integrity condition to be met, the PL (HPL and VPL) values must not exceed the Alarm Limits (AL) defined for a given flight stage [20]. The AL should be understood as the maximum allowable HPL and VPL value defined separately for operations NPA, APV-1 and LPV-200 [17]. Loss of integrity occurs when xPE $>$ xPL. Ratio of the positioning error to the corresponding PL value is expressed by SI (Safety Index) according to the formula [21]:

$x S I=\frac{x P E}{x P L}$,

where:

$x S I$ - safety index, horizontal or vertical, $x P E$ - horizontal or vertical positioning error,

$x P L$ - horizontal or vertical protection level.

There is a risk of MI (Misleading Information) when the SI value is greater than 0.75 . If, however, the ratio is greater than 1, then real MI or HMI (Hazardous Misleading Information) occurs.

Continuity is defined as e ability of the system (containing all the elements necessary to maintain the object's positioning in a given space) to provide a given function for the duration of the intended operation [17]. It is expressed by the probability of maintaining the certain system functions for the duration of the operation phase (assuming that the system was available at the beginning) and is predicted for the duration of the operation. The lack of continuity may occur when the receiver is unable to determine the position or when the PL values exceed the defined AL.

There are two types of loss of continuity [17]:

- long-term loss of continuity (lasting more than 3 seconds)

- independent loss of continuity (it constitutes loss of continuity lasting not less than 3 seconds, determined 
Table 1 Required values of quality parameters of the SoL service of the EGNOS system used in aviation [7, 20]

\begin{tabular}{|c|c|c|c|c|c|c|c|c|}
\hline $\begin{array}{c}\text { aircraft phase } \\
\text { of flight }\end{array}$ & $\begin{array}{c}\text { horizontal } \\
\text { accuracy } \\
95 \%\end{array}$ & $\begin{array}{c}\text { vertical } \\
\text { accuracy } \\
95 \%\end{array}$ & integrity & $\begin{array}{l}\text { time to } \\
\text { alert } \\
\text { (tta) }\end{array}$ & $\begin{array}{l}\text { horizontal } \\
\text { alarm limit } \\
\text { (hal) }\end{array}$ & $\begin{array}{l}\text { vertical } \\
\text { alarm limit } \\
\quad \text { (val) }\end{array}$ & continuity & availability \\
\hline $\begin{array}{c}\text { en-route (oceanic/ continental } \\
\text { low density) }\end{array}$ & $3.7 \mathrm{~km}$ & $\mathrm{n} / \mathrm{a}$ & $1-1 \times 10^{-7} / \mathrm{h}$ & $5 \min$ & $7.4 \mathrm{~km}$ & $\mathrm{n} / \mathrm{a}$ & $\begin{array}{l}1-1 \times 10^{-4} / \mathrm{h} \\
\text { to } 1-1 \times 10^{-8} / \mathrm{h}\end{array}$ & $\begin{array}{l}0.99 \text { to } \\
0.99999\end{array}$ \\
\hline en-route (continental) & & & & & $3.7 \mathrm{~km}$ & $\mathrm{n} / \mathrm{a}$ & & \\
\hline en-route, terminal & $0.74 \mathrm{~km}$ & $\mathrm{n} / \mathrm{a}$ & $1-1 \times 10^{-7} / \mathrm{h}$ & $15 \mathrm{~s}$ & $1.85 \mathrm{~km}$ & $\mathrm{n} / \mathrm{a}$ & $\begin{array}{l}1-1 \times 10^{-4} / \mathrm{h} \\
\text { to } 1-1 \times 10^{-8} / \mathrm{h}\end{array}$ & $\begin{array}{l}0.99 \text { to } \\
0.99999\end{array}$ \\
\hline $\begin{array}{l}\text { initial approach, intermediate } \\
\text { approach, non-precision } \\
\text { approach (npa), departure }\end{array}$ & $220 \mathrm{~m}$ & $\mathrm{n} / \mathrm{a}$ & $1-1 \times 10^{-7} / \mathrm{h}$ & $10 \mathrm{~s}$ & $556 \mathrm{~m}$ & $\mathrm{n} / \mathrm{a}$ & $\begin{array}{l}1-1 \times 10^{-4} / \mathrm{h} \\
\text { to } 1-1 \times 10^{-8} / \mathrm{h}\end{array}$ & $\begin{array}{l}0.99 \text { to } \\
0.99999\end{array}$ \\
\hline $\begin{array}{l}\text { approach operations with } \\
\text { vertical guidance (apv-1) }\end{array}$ & $16 \mathrm{~m}$ & $20 \mathrm{~m}$ & $\begin{array}{l}1-2 \times 10^{-7} \\
\text { in any } \\
\text { approach }\end{array}$ & $10 \mathrm{~s}$ & $40 \mathrm{~m}$ & $50 \mathrm{~m}$ & $\begin{array}{l}1-8 \times 10^{-6} \\
\text { per } 15 \mathrm{~s}\end{array}$ & $\begin{array}{l}0.99 \text { to } \\
0.99999\end{array}$ \\
\hline category I precision approach & $16 \mathrm{~m}$ & $\begin{array}{l}6.0 \mathrm{~m} \text { to } \\
4.0 \mathrm{~m}\end{array}$ & $\begin{array}{l}1-2 \times 10^{-7} \\
\text { in any } \\
\text { approach }\end{array}$ & $6 \mathrm{~s}$ & $40 \mathrm{~m}$ & $\begin{array}{c}35 \mathrm{~m} \text { to } \\
10 \mathrm{~m}\end{array}$ & $\begin{array}{l}1-8 \times 10^{-6} \\
\text { per } 15 \mathrm{~s}\end{array}$ & $\begin{array}{l}0.99 \text { to } \\
0.99999\end{array}$ \\
\hline
\end{tabular}

after the system has been available (PL $<\mathrm{AL})$ for at least 15 seconds).

Continuity risk is the probability of a detected but unscheduled navigation interruption after initiation of an operation. During the analysis performed, the long-term loss of continuity and independent loss of continuity were examined. Risk of the loss of continuity $P_{d i s c}$, which is related to independent loss of continuity and $P_{\text {slide }}$, which is related to the long-term loss of continuity, are given below.

Risk of loss of continuity $P_{\text {disc }}$ is expressed by Equation (10):

$$
P_{\text {disc }}=\frac{N_{\text {indep }}}{N_{\text {total }}} 15
$$

where:

$N_{\text {indep }}$ - number of independent single continuity breaks, $N_{\text {total }}$ - number of all the valid measurement epochs.

Risk of loss of continuity $P_{\text {slide }}$ can be determined according to:

$P_{\text {slide }}=\sum_{i=1}^{N_{d}} \frac{\max (15, \operatorname{disc}(i))}{N_{\text {total }}}$,

where:

$\operatorname{disc}(i)$ - duration of loss of continuity,

$N_{d}$ - number of single continuity breaks,

$N_{\text {total }}$ - number of all valid measurement epochs.

Availability of the navigation system is its ability to provide the required services and appropriate operation at the beginning of the planned operation [17]. It is also the ability of the system to provide the full-fledged services in a specific area. The service is available when the requirements for accuracy, integrity and continuity are met [21].

Availability of the GNSS system is a complex parameter to determine due to the movement of the satellites in relation to the area of operation and the long recovery time in case of a failure detection [22]. It is often determined based on modelling and analysing, rather than by measuring it. However, the real availability of the system can only be determined by calculations after its operation. The signal availability is the percentage of time in which the signal is transmitted from an external source in a form that is usable. It is a function of physical phenomena surrounding the system and the technical capabilities of transmitting devices. Studies on availability of the EGNOS system in its area of operation have been successively published by the ESSP (monthly and annual reports). However, it should be indicated that availability is a parameter, which should also be studied locally [23-24]. In the study performed as a part of this work, analysis of the EGNOS signal availability, local availability and operational availability were performed. Availability of the EGNOS signal $\left(A V_{S I S}\right)$ should be understood as the time ratio, in which at least one geostationary satellite transmits EGNOS messages $\left(\Sigma t_{V S}\right)$ to the time of complete test $\left(\Sigma t_{T S}\right)$, according to the formula [17]:

$A V_{\text {SIS }}=\frac{\Sigma t_{V S}}{\Sigma t_{T S}}$.

Availability of the Open Service $\left(A V_{O S}\right)$ is a ratio of the number of epochs, in which HPE $<3 \mathrm{~m}$ and VPE $<4 \mathrm{~m}\left(t_{O S}\right)$, to the number of all the measurement epochs $\left(t_{T S}\right)$ [21]:

$A V_{O S}=\frac{\Sigma t_{O S}}{\Sigma t_{T S}}$.

The operational availability of the EGNOS system $\left(S_{A V}\right)$ can be defined as a ratio of the number of samples that are available for a given operation to the total number of the valid epochs. This relationship can be described by [17, 21]:

$S_{A V}=\frac{\sum S_{O S}}{\sum S_{T S}}$,

where:

$S_{A V}$ - operational availability,

$\Sigma S_{T S}$ - the number of samples that are available for the operation (number of epochs for which in the case of NPA, HPL $<556 \mathrm{~m}$, while in the case of APV-1 and LPV-200, $\mathrm{HPL}<40 \mathrm{~m}$ and VPL $<50 \mathrm{~m}$ ), 

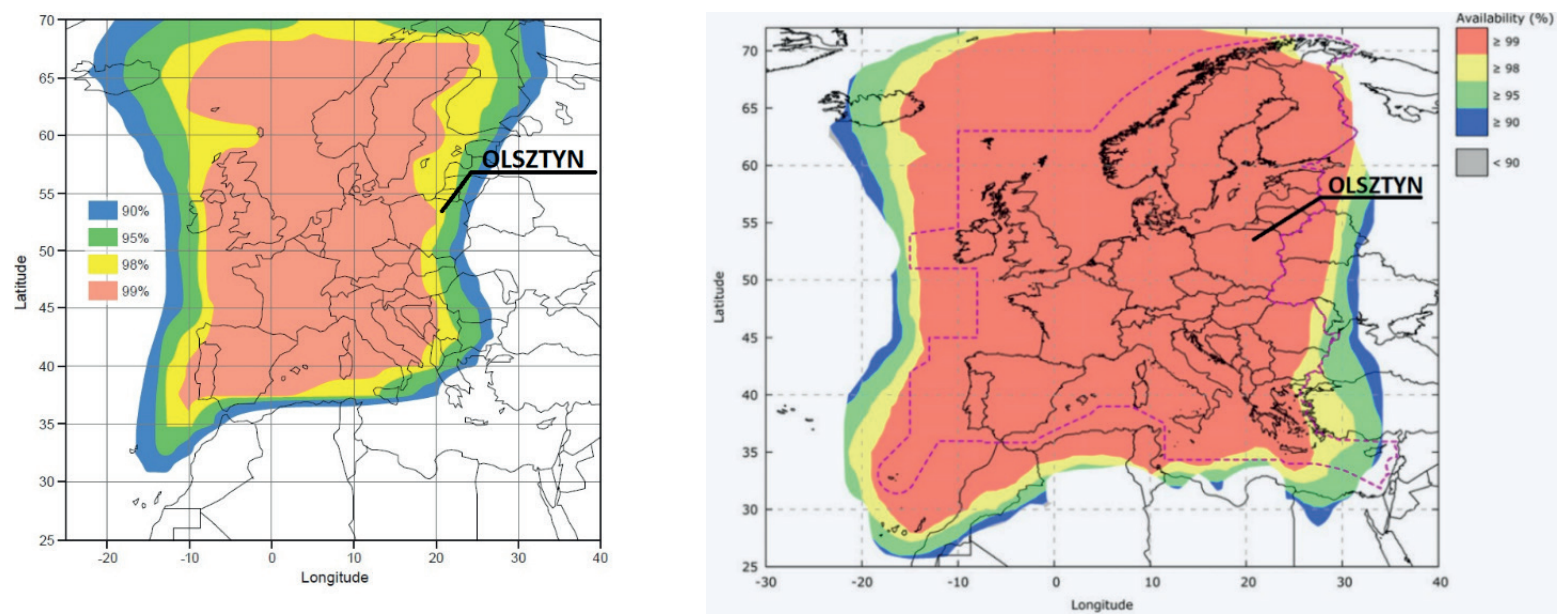

Figure 1 Location of the examined station in Olsztyn against the availability of the EGNOS approach with APV-1 before 2012 (left) and current availability of the EGNOS approach with LPV-200 service (right) [7-8]
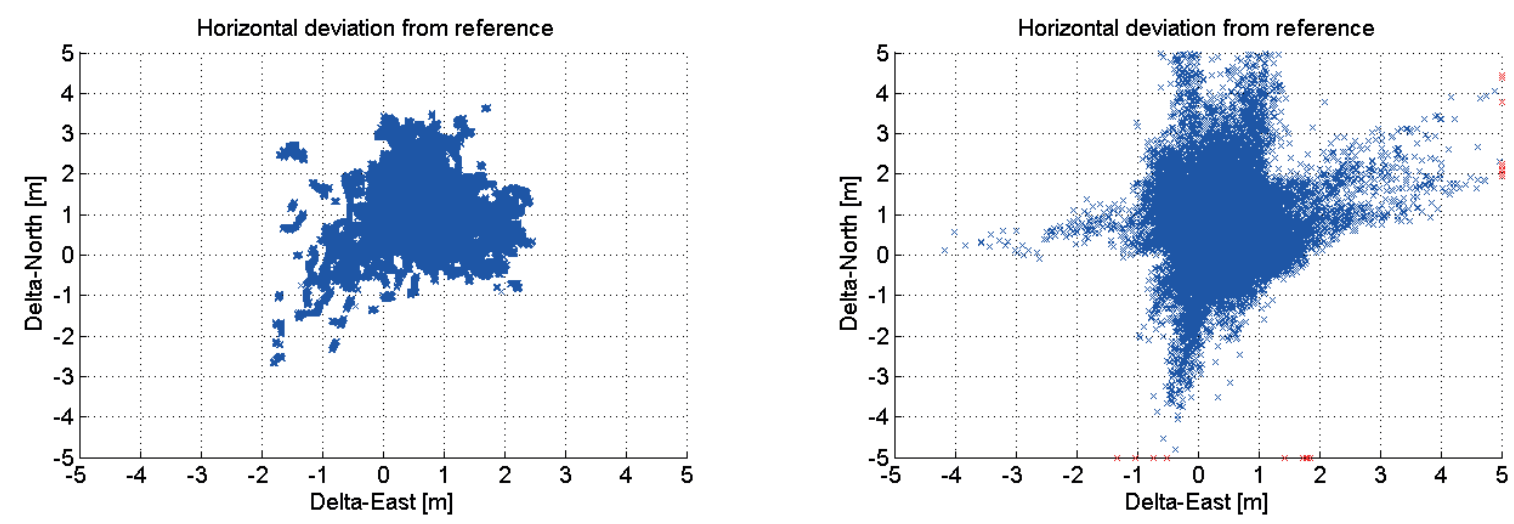

Figure 2 Results of the analyses of the horizontal accuracy of autonomous GPS (left) and GPS / EGNOS (right) positioning during the period 10-14 Dec 2012

$\Sigma S_{O S}$ - sum of all the available measurement epochs.

The quality of the positioning service must comply with existing requirements for the use of the SBAS systems in aviation [20]. Table 1 contains defined values of parameters characterizing accuracy, integrity, continuity and availability of positioning using the SoL service.

\section{Research and results}

In order to analyse quality of the GPS / EGNOS positioning, measurement data, collected with the Septentrio AsteRx2 receiver installed at the Warmia-Mazury Aeroclub in Olsztyn (north-eastern Poland), were used. Figure 1 presents location of the examined station against the availability of the EGNOS approach with APV-1 before 2012 and current availability of EGNOS approach with LPV-200 service.

Five days long data sets, from periods that were characterized by operation of different versions of the EGNOS system, were selected for testing. These data sets come from: 10-14 Dec 2012 (ESR V2.3.1), 10-14 Dec 2014 (ESR V2.3.2), 10-14 Dec 2015 (ESR V2.4.1 M), 10-14 Dec 2017 (ESR V2.4.1 N) and 10-14 Dec 2018 (ESR V2.4.1 N). Due to aviation applications, the registration interval was set to 1 second and the elevation mask was set to 5 degrees. When selecting the location of the receiver, the impact of a possible multipath effect and other satellite signal interference on the measurement results was taken into account.

The data was examined using the latest version of the software for analysing the quality of the SBAS positioning in aviation - PEGASUS v.19.07.03, Septentrio Post Processing SDK package and the self-developed tool - PP_SBAS_ Analyzer.

The analyses were carried out in two calculation variants:

- GPS / EGNOS positioning in the APV-1 and LPV-200 mode, using data from the EGNOS geostationary satellites in the positioning process,

- $\quad$ autonomous GPS in the NPA positioning mode, using only data from the GPS satellites.

In the case of the NPA configuration, only measurement periods for which HPL $<556 \mathrm{~m}$ were taken into account. The APV-1 variant is characterized by periods for which HPL $<40 \mathrm{~m}$ and VPL $<50 \mathrm{~m}$. For the LPV-200 operations, $\mathrm{HPL}<40 \mathrm{~m}$ and $\mathrm{VPL}<35 \mathrm{~m}$.

\subsection{GPS autonomous vs GPS / EGNOS positioning}

In the first stage of research the preliminary comparison of the GPS / EGNOS and autonomous GPS positioning is 

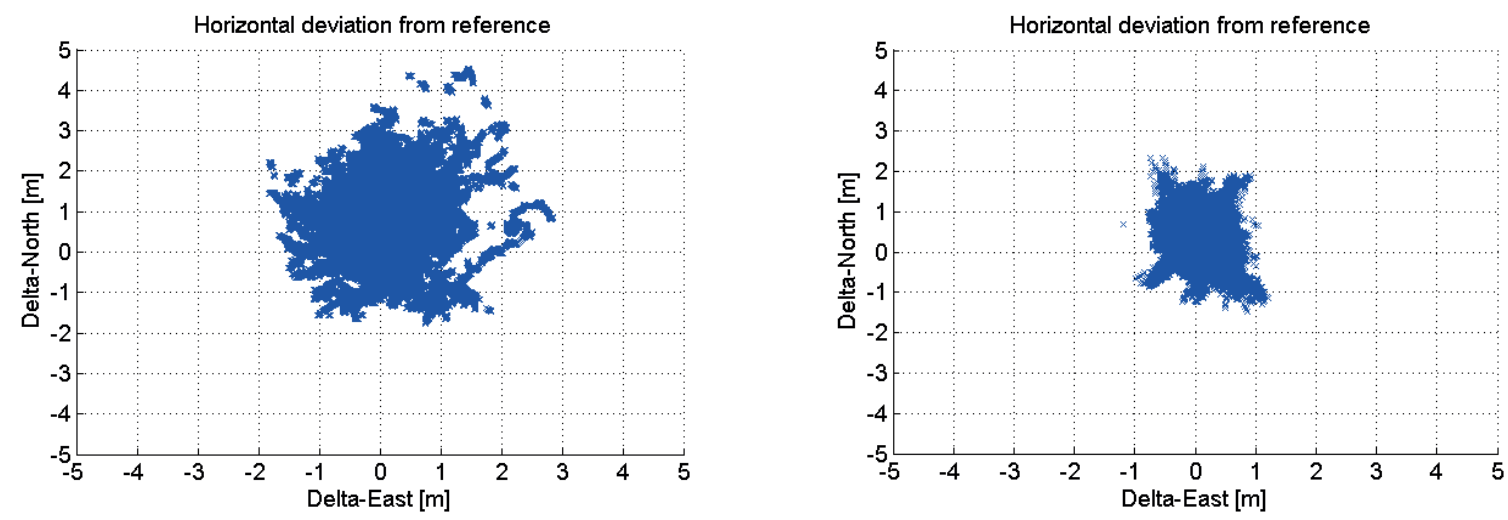

Figure 3 Results of the analyses of the horizontal accuracy of autonomous GPS (left) and GPS / EGNOS (right) positioning during the period 10-14 Dec 2014
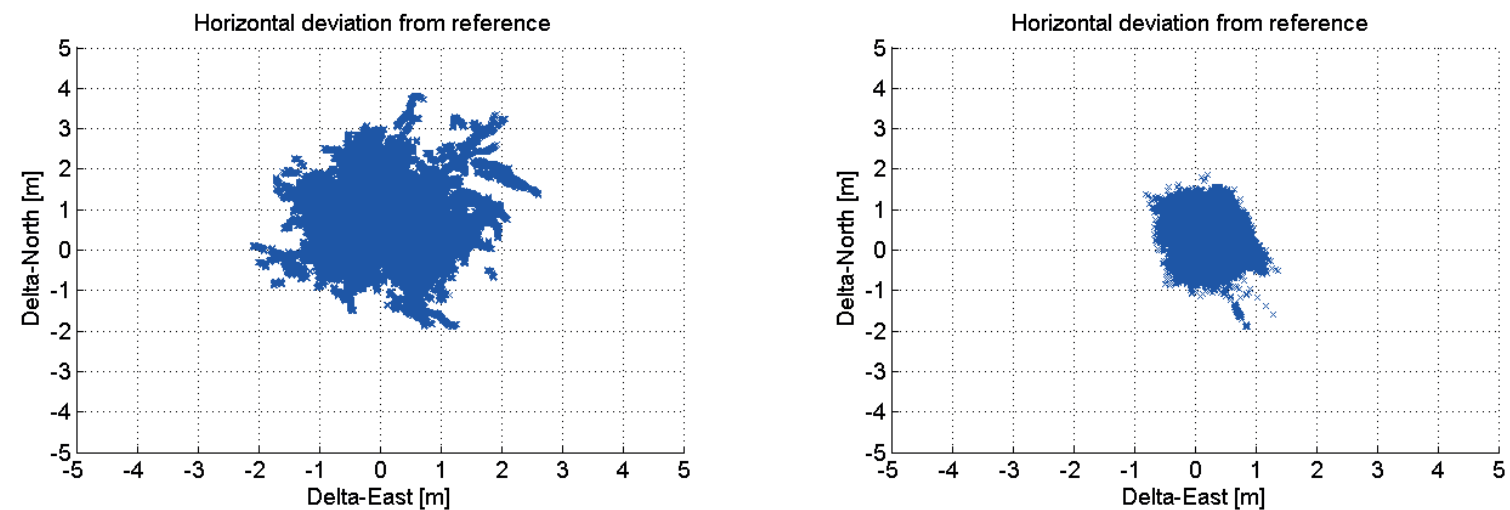

Figure 4 Results of the analyses of the horizontal accuracy of autonomous GPS (left) and GPS / EGNOS (right) positioning during the period 10-14 Dec 2015
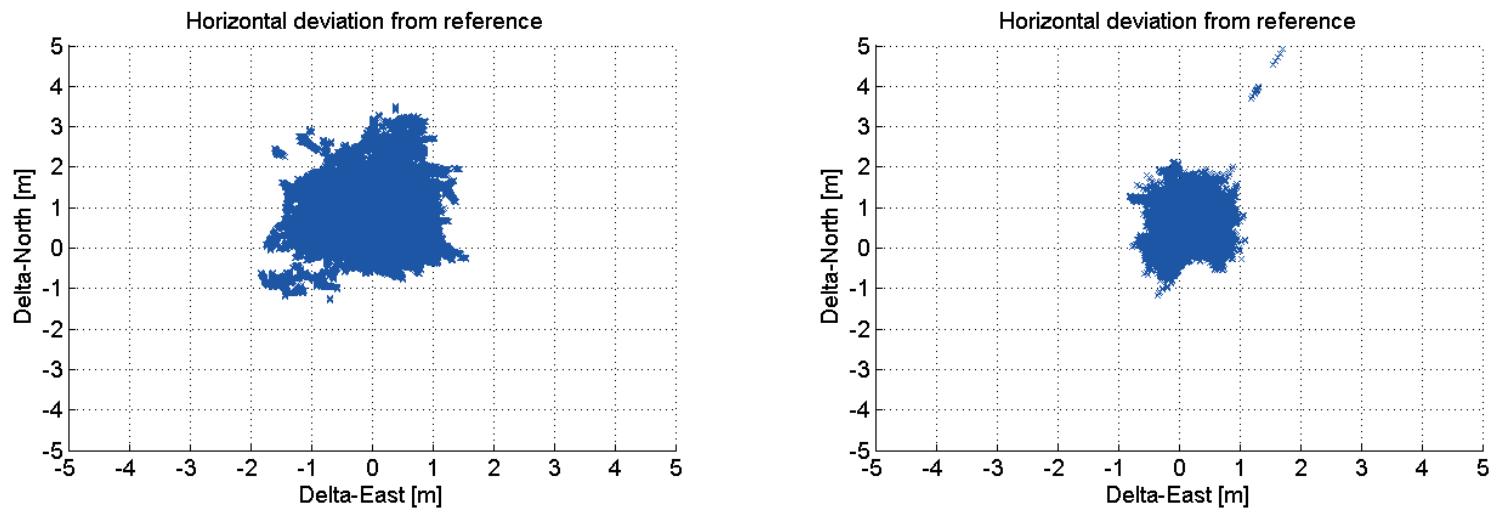

Figure 5 Results of the analyses of the horizontal accuracy of autonomous GPS (left) and GPS / EGNOS (right) positioning during the period 10-14 Dec 2017
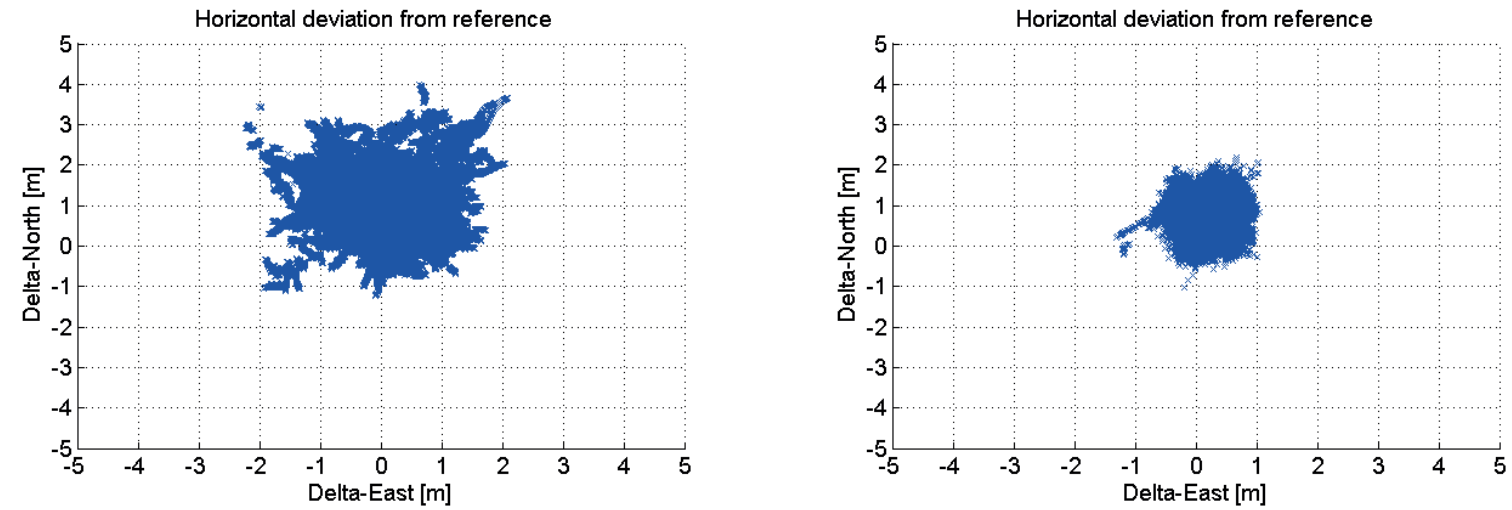

Figure 6 Results of the analyses of the horizontal accuracy of autonomous GPS (left) and GPS / EGNOS (right) positioning during the period 10-14 Dec 2018 
Table 2 Results of 95\% accuracy values (comparison of autonomous GPS and GPS / EGNOS positioning)

\begin{tabular}{|c|c|c|c|c|c|c|}
\hline \multicolumn{2}{|r|}{ parameter } & $\begin{array}{c}\text { 10-14 December } \\
2012\end{array}$ & $\begin{array}{c}\text { 10-14 December } \\
2014\end{array}$ & $\begin{array}{c}\text { 10-14 December } \\
2015\end{array}$ & $\begin{array}{c}\text { 10-14 December } \\
2017\end{array}$ & $\begin{array}{c}\text { 10-14 December } \\
2018\end{array}$ \\
\hline \multirow{4}{*}{ accuracy } & HPE 95\% GPS (m) & 2.82 & 2.33 & 2.07 & 2.01 & 2.18 \\
\hline & $\begin{array}{c}\text { HPE 95\% GPS/ } \\
\text { EGNOS (m) }\end{array}$ & 1.41 & 0.97 & 0.98 & 1.12 & 1.21 \\
\hline & VPE 95\% GPS (m) & 5.28 & 6.52 & 6.17 & 4.51 & 4.37 \\
\hline & $\begin{array}{c}\text { VPE } 95 \% \text { GPS/ } \\
\text { EGNOS (m) }\end{array}$ & 1.53 & 1.37 & 1.39 & 1.21 & 1.23 \\
\hline
\end{tabular}

Table 3 GPS / EGNOS positioning accuracy results

\begin{tabular}{|c|c|c|c|c|c|}
\hline parameter & $\begin{array}{c}\text { 10-14 December } \\
2012\end{array}$ & $\begin{array}{c}\text { 10-14 December } \\
2014\end{array}$ & $\begin{array}{c}\text { 10-14 December } \\
2015\end{array}$ & $\begin{array}{c}\text { 10-14 December } \\
2017\end{array}$ & $\begin{array}{c}\text { 10-14 December } \\
2018\end{array}$ \\
\hline HPE 95\% APV-1 (m) & 1.40 & 0.97 & 0.98 & 1.12 & 1.21 \\
\hline HPE 95\% LPV-200 (m) & 1.40 & 0.97 & 0.98 & 1.12 & 1.21 \\
\hline VPE 95\% APV-1 (m) & 1.59 & 1.37 & 1.39 & 1.21 & 1.23 \\
\hline VPE 95\% LPV-200 (m) & 1.59 & 1.37 & 1.39 & 1.21 & 1.23 \\
\hline $\mathrm{HPE}_{\max }(\mathrm{m})$ & 19.10 & 3.55 & 2.08 & 5.20 & 2.30 \\
\hline $\mathrm{VPE}_{\max }(\mathrm{m})$ & 51.48 & 3.37 & 3.42 & 6.26 & 1.15 \\
\hline $\mathrm{HPE}_{\text {mean }}(\mathrm{m})$ & 0.87 & 0.54 & 0.57 & 0.67 & 0.74 \\
\hline $\mathrm{VPE}_{\text {mean }}(\mathrm{m})$ & 0.64 & 0.57 & 0.54 & 0.48 & 0.50 \\
\hline $\mathrm{HPE}_{\text {stand. dev. }}(\mathrm{m})$ & 0.32 & 0.25 & 0.24 & 0.25 & 0.26 \\
\hline $\mathrm{VPE}_{\text {stand. dev. }}(\mathrm{m})$ & 0.50 & 0.42 & 0.43 & 0.38 & 0.39 \\
\hline
\end{tabular}

presented. Such an analysis allowed for the evaluation of the EGNOS system itself and elimination of the possibility of the local measurement conditions impact (e.g. multipath effect) on the measurement results. For this purpose, horizontal positioning accuracy analyses were done and compiled in Figures 2-6.

Based on the horizontal analyses, it is possible to observe a similar value of the HPE (up to about $4 \mathrm{~m}$ ) for the autonomous GPS variant in all of the examined measurement sessions. At the same time, the GPS / EGNOS HPE seems to be more differentiated for the test sessions. Noteworthy is the high value of GPS / EGNOS positioning errors in 2012 (even above $5 \mathrm{~m}$ ). During the measurement sessions in subsequent years, values of these errors were more concentrated and were within $2 \mathrm{~m}$ (except for several epochs in 2017). The results obtained may indicate a significant impact of the change in the EGNOS software on accuracy since 2014. Table 2 presents results of the horizontal and vertical analyses of the GPS autonomous and GPS / EGNOS positioning accuracy.

Analysis of the HPE 95\% and VPE 95\% values showed similar improvement in GPS / EGNOS positioning compared to autonomous GPS in each measurement session. In the case of horizontal positioning, the ratio of the HPE 95\% for GPS / EGNOS to HPE 95\% for autonomous GPS is similar in each session (about 0.50 ). The situation is similar in the case of the vertical analysis: the ratio of VPE 95\% for GPS / EGNOS to VPE 95\% for autonomous GPS is about 0.30 in each of the examined sessions. Therefore, these analyses did not show a significant improvement in the quality of positioning in measurement sessions related to different versions of the EGNOS system. Considering the significant differences in horizontal positioning errors presented in horizontal plots (Table 2), it can be stated that the modernization of the EGNOS system after 2012 significantly reduced the maximum values of positioning errors.

In the next stage of research, changes in the GPS / EGNOS positioning quality related to the implementation of subsequent versions of the EGNOS system were analysed in detail.

\subsection{GPS/EGNOS accuracy analysis}

The first quality parameter analysed is positioning accuracy. Results of the GPS / EGNOS positioning accuracy analysis are presented in Table 3:

Results of the APV-1 and LPV-200 horizontal and vertical accuracy analyses are the same. The maximum xPE $95 \%$ values were obtained for the 2012 session (HPE $95 \%=1.40 \mathrm{~m}$, VPE $95 \%=1.59 \mathrm{~m}$ ). In the same measurement session, maximum positioning errors were also obtained $\left(\mathrm{HPE}_{\max }=19.10 \mathrm{~m}, \mathrm{VPE}_{\max }=51.48 \mathrm{~m}\right)$. The results from the other measurement sessions are at a similar level, significantly better than that from 2012 .

\subsection{GPS/EGNOS integrity analysis}

The next stage of research is analysis of parameters characterizing the integrity of GPS / EGNOS positioning. This was carried out using Stanford diagrams presenting 

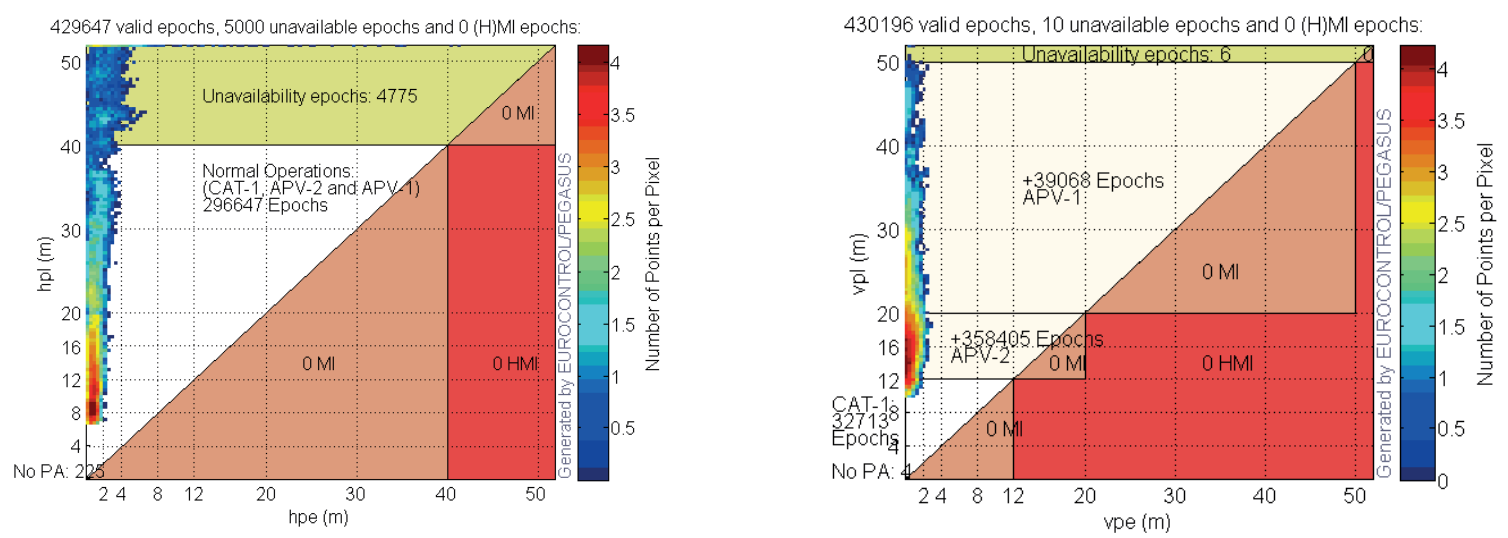

Figure 7 Horizontal (left) and Vertical (right) Stanford diagrams related to integrity analysis for the period 10-14 Dec 2012
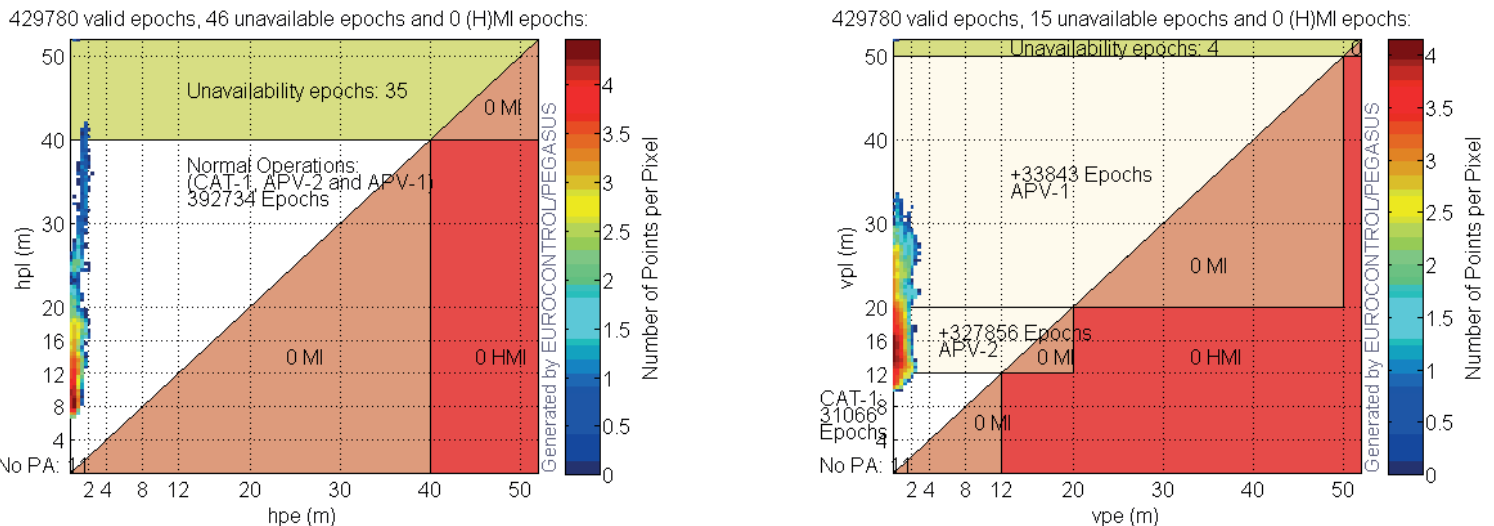

Figure 8 Horizontal (left) and Vertical (right) Stanford diagrams related to integrity analysis for the period 10-14 Dec 2014
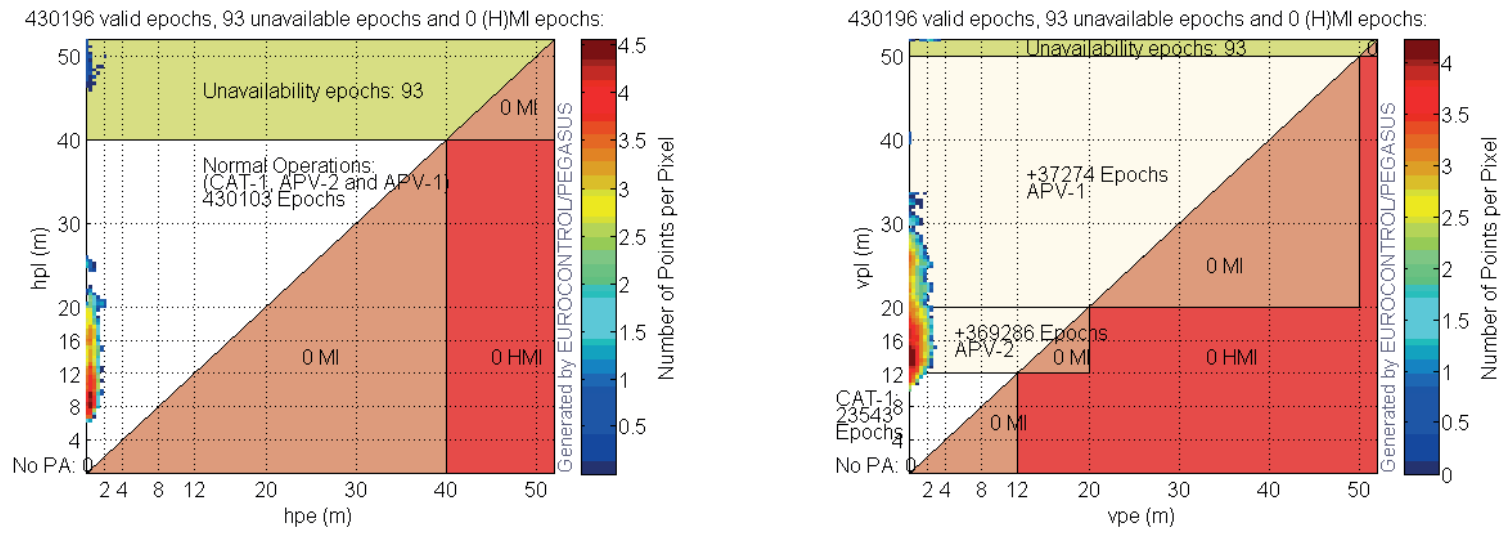

Figure 9 Horizontal (left) and Vertical (right) Stanford diagrams related to integrity analysis for the period 10-14 Dec 2015
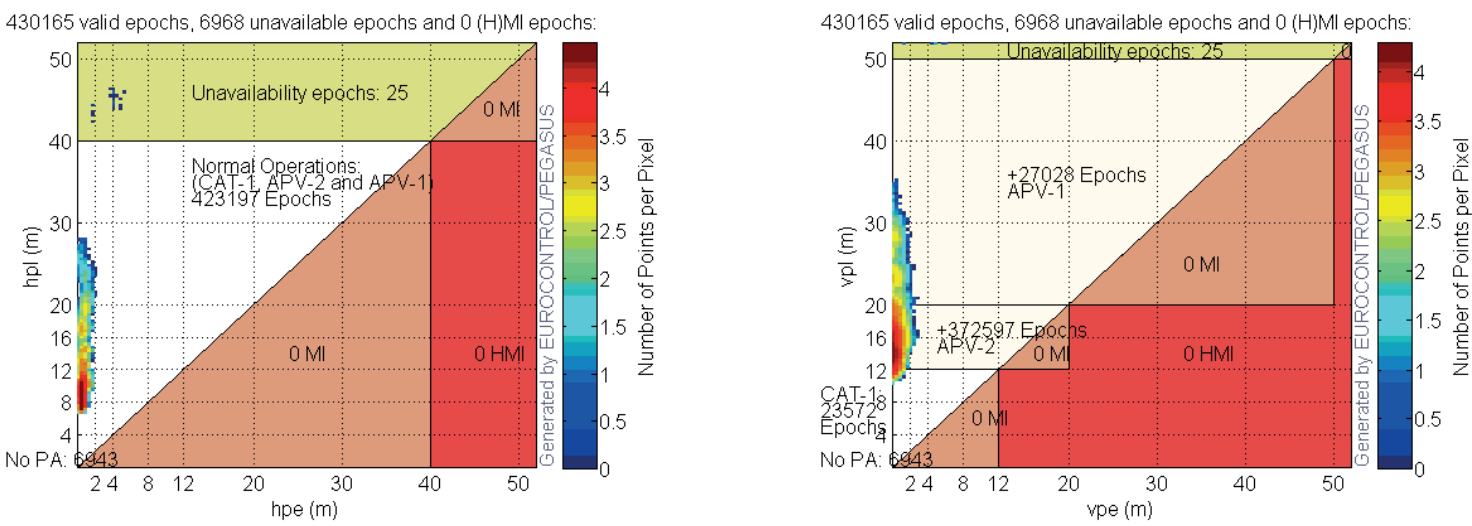

Figure 10 Horizontal (left) and Vertical (right) Stanford diagrams related to integrity analysis for the period 10-14 Dec 2017 

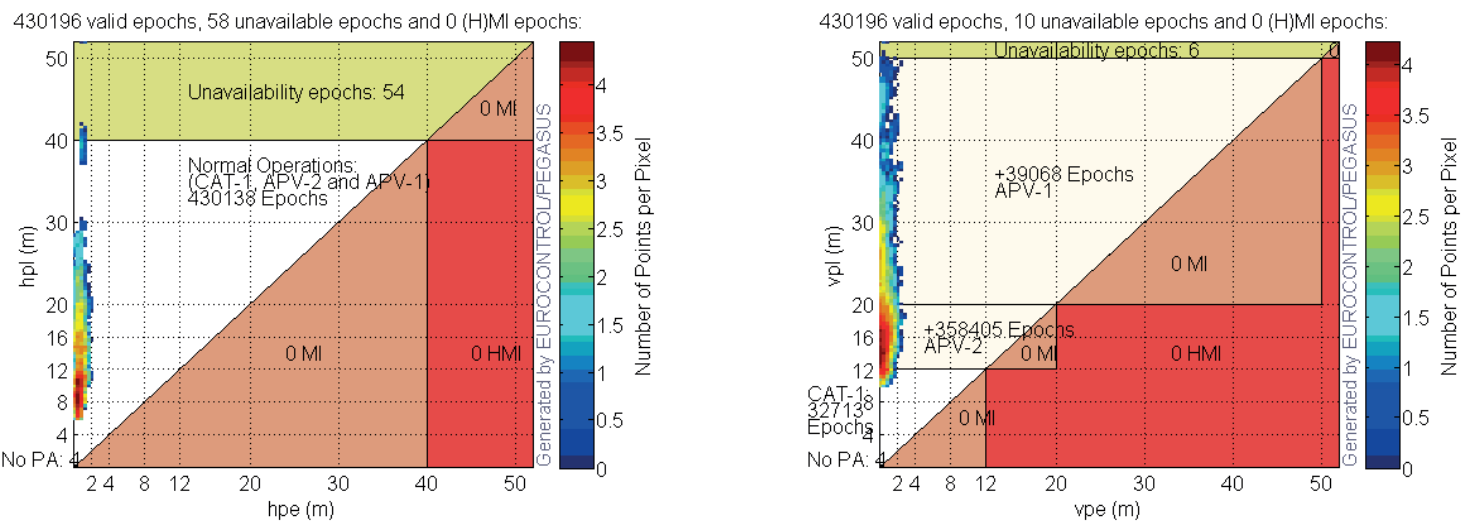

Figure 11 Horizontal (left) and Vertical (right) Stanford diagrams related to integrity analysis for the period 10-14 Dec 2018

Table 4 Results of the integrity analysis

\begin{tabular}{cccccc}
\hline parameter & 10-14 December & 10-14 December & 10-14 December & 10-14 December & 10-14 December \\
& 2012 & 2014 & 2015 & 2017 & 2018 \\
\hline HPL 99\% (m) & 19.56 & 19.39 & 18.66 & 19.86 & 21.40 \\
VPL 99\% (m) & 28.44 & 26.15 & 26.45 & 28.02 & 30.41 \\
HPL $_{\text {min }}(\mathrm{m})$ & 6.11 & 6.77 & 6.34 & 6.43 & 5.63 \\
VPL $_{\text {min }}(\mathrm{m})$ & 10.21 & 10.01 & 9.92 & 10.27 & 9.71 \\
HPL $_{\text {mean }}(\mathrm{m})$ & 10.53 & 10.21 & 10.00 & 9.68 & 10.13 \\
VPL $_{\text {mean }}(\mathrm{m})$ & 15.87 & 15.51 & 15.57 & 15.36 & 15.87 \\
HPL $_{\text {stand. dev. }}(\mathrm{m})$ & 3.06 & 2.69 & 2.70 & 2.56 & 3.09 \\
VPL $_{\text {stand. dev }}(\mathrm{m})$ & 3.71 & 3.21 & 3.25 & 3.08 & 3.92 \\
HSI LPV-200 100\% & 0.20 & 0.16 & 0.17 & 0.18 & 0.21 \\
VSI LPV-200 100\% & 0.19 & 0.22 & 0.20 & 0.18 & 0.17 \\
\hline
\end{tabular}

the values of HPL, VPL, HPE and VPE on the background of requirements at individual stages of aviation operations. Figures 7-11 present results of the integrity analysis.

The worst results were obtained for data from 2012. In this period 4775 measurement epochs did not meet the requirements of horizontal accuracy for procedures in accordance with APV-1, which coincides with the worst results obtained for this period from the accuracy analysis. The analyses carried out for the rest of periods are characterized by much better results, all at a similar level. The number of epochs not available for APV-1 procedures ranges from a few to about 100. Table 4 presents results of a detailed analysis related to the HPL and VPL values.

The HPL 99\% and VPL 99\% values are at a comparable level during all of the measurement sessions. Analysis of the HSI and VSI values showed very good and similar results in all the measurement sessions (about 0.20 for both horizontal and vertical analysis). These results met the integrity requirements for the safe air navigation. There was no risk of MI (SI values greater than 0.75 ) in any of the measurement sessions.

The research was additionally extended by analysis of a parameter characterizing differences between the protection levels and positioning errors. The SI coefficient values should be as low as possible for air navigation applications. However, protection levels that are too high, in relation to actual positioning accuracy, can have a negative impact on the optimal application possibilities of the SBAS. Therefore, it was proposed to introduce parameters presenting differences between the protection levels and the real positioning errors:

$\triangle H P=H P L-H P E$,

$\triangle V P=V P L-V P E$.

Such analysis allows to assess the quality of the integrity model used in the examined cases. Values of $\Delta \mathrm{HP}$ and $\Delta \mathrm{VP}$ were determined for each of the tested measurement sessions. Then, the mean values $\left(\Delta \mathrm{HP}_{\text {mean }}\right.$ and $\left.\Delta \mathrm{VP}_{\text {mean }}\right)$ and their median $\left(\Delta \mathrm{HP}_{\text {median }}\right.$ and $\left.\Delta \mathrm{VP}_{\text {median }}\right)$ of obtained values were determined. Table 5 shows the values obtained from the analysis for $\Delta \mathrm{HP}$ and $\Delta \mathrm{VP}$.

The mean values of $\Delta \mathrm{HP}$ and $\Delta \mathrm{VP}$ are the largest for the 2012 session ( $10.94 \mathrm{~m}$ and $17.33 \mathrm{~m}$ respectively), which is due to quite large maximum positioning errors (HPE and VPE) for these measurement data. For the remaining sessions in the years 2014, 2015, 2017 and 2018 the average values of horizontal and vertical differences are smaller and are at a similar level (from $8.80 \mathrm{~m}$ to $9.71 \mathrm{~m}$ for the horizontal parameter and from $14.55 \mathrm{~m}$ to $15.30 \mathrm{~m}$ for the vertical parameter). 
Table 5 Results of the analysis of differences between the $x P L$ and $x P E$.

\begin{tabular}{|c|c|c|c|c|c|}
\hline parameter & $\begin{array}{c}\text { 10-14 December } \\
2012\end{array}$ & $\begin{array}{c}\text { 10-14 December } \\
2014\end{array}$ & $\begin{array}{c}\text { 10-14 December } \\
2015\end{array}$ & $\begin{array}{c}\text { 10-14 December } \\
2017\end{array}$ & $\begin{array}{c}\text { 10-14 December } \\
2018\end{array}$ \\
\hline$\Delta \mathrm{HP}_{\text {mean }}(\mathrm{m})$ & 10.94 & 9.71 & 9.40 & 8.80 & 9.35 \\
\hline$\Delta \mathrm{VP}_{\text {mean }}(\mathrm{m})$ & 17.33 & 14.93 & 14.96 & 14.55 & 15.30 \\
\hline$\Delta \mathrm{HP}_{\text {median }}(\mathrm{m})$ & 8.79 & 9.09 & 8.54 & 8.50 & 8.78 \\
\hline$\Delta \mathrm{VP}_{\text {median }}(\mathrm{m})$ & 14.33 & 14.48 & 14.20 & 14.17 & 14.60 \\
\hline
\end{tabular}

Table 6 The results of the availability analysis

\begin{tabular}{|c|c|c|c|c|c|}
\hline parameter & $\begin{array}{c}\text { 10-14 December } \\
2012\end{array}$ & $\begin{array}{c}\text { 10-14 December } \\
2014\end{array}$ & $\begin{array}{c}\text { 10-14 December } \\
2015\end{array}$ & $\begin{array}{c}\text { 10-14 December } \\
2017\end{array}$ & $\begin{array}{c}\text { 10-14 December } \\
2018\end{array}$ \\
\hline signal in space availability & 0.997916 & 0.996143 & 1.00000 & 0.996860 & 0.999991 \\
\hline local availability & 0.996421 & 0.991146 & 0.995824 & 0.992712 & 0.995815 \\
\hline operational availability APV-1 & 0.992581 & 0.991053 & 0.995609 & 0.992623 & 0.995685 \\
\hline operational availability LPV-200 & 0.990833 & 0.990910 & 0.995569 & 0.990623 & 0.991692 \\
\hline
\end{tabular}

Table 7 Results of the continuity analysis

\begin{tabular}{|c|c|c|c|c|c|}
\hline parameter & $\begin{array}{c}\text { 10-14 December } \\
2012\end{array}$ & $\begin{array}{c}\text { 10-14 December } \\
2014\end{array}$ & $\begin{array}{c}\text { 10-14 December } \\
2015\end{array}$ & $\begin{array}{l}\text { 10-14 December } \\
2017\end{array}$ & $\begin{array}{c}\text { 10-14 December } \\
2018\end{array}$ \\
\hline $\begin{array}{l}\text { all discontinuity events } \\
\text { APV-1 }\end{array}$ & 8 & 17 & 1 & - & 7 \\
\hline $\begin{array}{l}\text { all discontinuity events } \\
\text { LPV-200 }\end{array}$ & 23 & 13 & 2 & - & 9 \\
\hline $\begin{array}{l}\text { long discontinuity events } \\
\text { APV-1 }\end{array}$ & 5 & 4 & 1 & - & 1 \\
\hline $\begin{array}{l}\text { long discontinuity events } \\
\text { LPV-200 }\end{array}$ & 6 & 4 & 2 & - & 6 \\
\hline $\begin{array}{l}\text { independent discontinuity } \\
\text { events APV-1 }\end{array}$ & 3 & 3 & 1 & - & 1 \\
\hline $\begin{array}{l}\text { independent discontinuity } \\
\text { events LPV-200 }\end{array}$ & 3 & 3 & 2 & - & 1 \\
\hline$P_{d i s c}$ APV-1 & 0.000188652 & 0.000105107 & 0.000034875 & - & 0.000034873 \\
\hline$P_{d i s c}$ LPV-200 & 0.000188984 & 0.000105122 & 0.000069754 & - & 0.000210079 \\
\hline$P_{\text {slide }}$ APV-1 & 0.000357782 & 0.000226564 & 0.000034875 & - & 0.000255733 \\
\hline$P_{\text {slide }}$ LPV-200 & 0.000198545 & 0.000175204 & 0.000069754 & - & 0.000837980 \\
\hline
\end{tabular}

On the other hand, the median values of the $\Delta \mathrm{HP}$ and $\Delta \mathrm{VP}$ are at a similar level for each measurement session (from $8.50 \mathrm{~m}$ to $9.09 \mathrm{~m}$ for horizontal parameter and from $14.17 \mathrm{~m}$ to $14.60 \mathrm{~m}$ for vertical parameter). These results are due to the fact that the median values are resistant to the extreme values of $\Delta \mathrm{HP}$ and $\Delta \mathrm{VP}$.

The results of the $\Delta \mathrm{HP}$ and $\Delta \mathrm{VP}$ analyses showed a significant improvement in the performance of the integrity model after 2012, which resulted in better alignment of the protection levels with positioning errors.

\subsection{GPS/EGNOS availability analysis}

According to [21], the time at which the EGNOS data is transmitted via at least one geostationary satellite was analysed. The PRN 120 satellite was selected as the basic satellite for the periods 10-14 Dec 2012, 10-14 Dec 2014 and 10-14 Dec 2015, while the satellite PRN136 was selected for the periods 10-14 Dec 2017 and 10-14 Dec 2018.

Table 6 presents the results of the availability analysis prepared based on observations carried out on 10-14 Dec in 2012, 2014, 2015, 2017 and 2018. Signal availability, local availability, APV-1 operational availability and operational availability of LPV-200 were examined.

Availability of the EGNOS Signal in Space in each of the examined periods obtains a result close to $100 \%$. Local availability, operational availability of the EGVOS APV-1 and LPV-200 reaches the better result than $99 \%$ in each measurement session tested, which meets the requirements 
of the guidelines for the EGNOS applications in aviation [17].

\subsection{GPS/EGNOS continuity analysis}

In the studies, occurrence of all the cases of the continuity loss for the APV-1 and LPV-200, i.e. long-term phenomena of loss of continuity (APV-1 and LPV-200), independent phenomena of loss of continuity (APV-1 and LPV-200), risk of loss of continuity P_disc, P_slide (APV-1 and LPV-200) were analysed. In the case of the APV-1 variant, only the measurement periods for which the APV-1 solution was available (HPL $<40 \mathrm{~m}$ and VPL $<50 \mathrm{~m}$ ) were included in the calculation. The LPV-200 variant covers all the measurement epochs for which HPL $<40 \mathrm{~m}$ and VPL $<35 \mathrm{~m}$. Table 7 presents results of the EGNOS system continuity analysis over the periods considered.

Only in the 2017 session there were no instances of loss of continuity. Most of them occurred in the session of 2014 (17 cases). Due to the diversity of results in individual sessions, it was not possible to combine results of the continuity test with the modernization of the EGNOS system. The EGNOS system, according to requirements, can be used if $P_{\text {disc }}$ APV- $1<8 \times 10^{-6}$. The same requirements must be met for the LPV-200 operations. Thus, the positioning results of each measurement session do not meet the requirements for GPS / EGNOS APV-1 and LPV-200 positioning continuity. It should be noted, however, that measurement sessions lasting 5 days are not long enough to test the continuity of the GPS / EGNOS positioning. Thus, the results obtained can only be an indication of a problem that should be further investigated.

\section{Conclusions}

The analysis results presented in the article may suggest the readiness of the EGNOS system for applications using APV-1 and LPV-200 aviation procedures. The presented results of the analysis carried out in 2012, 2014, 2015, 2017 and 2018 indicate an improvement of the GPS / EGNOS positioning since 2014, which has significantly reduced value of the maximum positioning errors. For the safe air navigation, horizontal and vertical positioning accuracy of a few meters is sufficient. Much more important is the integrity of navigation data received by pilots through navigation devices. Results of analyses confirm that the integrity requirements for the safe air navigation are met. Additionally, the authors proposed an introduction of new parameters $\Delta \mathrm{HP}$ and $\Delta \mathrm{VP}$, which show the differences between the protection levels and real positioning errors. This comparison allows to assess the quality of the integrity model used in the analysed cases. Values of the $\Delta \mathrm{HP}$ and $\Delta \mathrm{VP}$ parameters show a great improvement in functioning of the GPS/EGNOS integrity model after 2012. Results of the continuity analysis indicate disturbances in the operation of the system that are not associated with software upgrades occurring with different versions of the EGNOS system. The availability analysis presents satisfactory results for applications in the APV-1 and LPV-200 procedures.

\section{References}

[1] JAIN, C., BAGCHI, S. GNSS based ionosphere characterization for SBAS. International Journal of Engineering Technology Science and Research [online]. 2018, 5(3), p. 788-796 [accessed 2020-01-12]. ISSN 2394 - 3386. Available from: http://www.ijetsr.com/images/short_pdf/1521730491_788-796-dyp177_ijetsr.pdf

[2] EL-MOWAFY, A., WANG, K. Second generation SBAS-performance analysis and bridging positioning and integrity monitoring during SBAS outages in the urban environment. In: 32nd International Technical Meeting of the Satellite Division of the Institute of Navigation ION GNSS+ 2019: proceedings. 2019. ISBN: 0-936406-23-2, p. 2842-2854.

[3] IMPARATO, D., EL-MOWAFY, A., RIZOS, C., WANG, J. Vulnerabilities in SBAS and RTK positioning in intelligent transport systems: an overview. In: International Global Navigation Satellite Systems Association IGNSS Symposium 2018: proceedings [online] [accessed 2020-01-11]. 2018. Available from: http://www.ignss2018.unsw.edu.au/sites/ ignss2018/files/u80/Papers/IGNSS2018_paper_10.pdf

[4] LI, L., JIA, C., ZHAO, L., CHENG, J., LIU, J., DING, J. Real-time single frequency precise point positioning using SBAS corrections. Sensors [online]. 2016, 16(8), 1261 [accessed 2020-01-11]. ISSN 1424-8220. Available from: https://doi.org/10.3390/s16081261

[5] ALLIEN, A., TAILLANDER, C., CAPO, C. User guide for EGNOS application development - ESA [online] [accessed 2020-01-03]. 2009. Available from: https://op.europa.eu/en/publication-detail/-/publication/9028327b-8122-4cfc-97a8$4243 \mathrm{c} 7 \mathrm{~d} 78039$

[6] About EGNOS [online] [accessed 2020-01-05]. Available from: http://egnos-user-support.essp-sas.eu/new_egnos_ ops/?q=content/about-egnos

[7] GSA - European global navigation satellite systems agency. Safety of life service definition document [online] [accessed 2019-12-20]. V 3.3. 2019. Available from: https://egnos-user-support.essp-sas.eu/new_egnos_ops/sites/default/files/ library/official_docs/egnos_sol_sdd_in_force.pdf

[8] GSA - European Commission. Safety of life service definition document. V 1.0. 2011. 
[9] ESSP ready to provide LPV-200 [online] [accessed 2012-01-08]. Available from: https://ec.europa.eu/transport/modes/air/ ses/ses-award-2016/projects/essp_en 2019

[10] CIECKO, A., GRUNWALD, G. Klobuchar, NeQuick G, and EGNOS ionospheric models for GPS/EGNOS single-frequency positioning under 6-12 September 2017 space weather events. Applied Sciences [online]. 2020, 10, 1553 [accessed 202003-10]. ISSN 2076-3417. Available from: https://doi.org/10.3390/app10051553

[11] GRUNWALD, G., BAKULA, M., CIECKO, A., KAZMIERCZAK, R. Examination of GPS/EGNOS integrity in north-eastern Poland. IET Radar Sonar and Navigation [online]. 2016, 10(1), 114 [accessed 2020-01-06]. ISSN 1751-8784. Available from: http://dx.doi.org/10.1049/iet-rsn.2015.0053

[12] GRUnWALD, G., BAKUlA, M., CIECKO, A. Study of EGNOS accuracy and integrity in eastern Poland. The Aeronautical Journal [online]. 2016, 120(1230), p. 1275-1290 [accessed 2020-01-06]. ISSN: 2059-6464. Available from: https://doi.org/10.1017/aer.2016.66

[13] SPECHT, M. Method of evaluating the positioning system capability for complying with the minimum accuracy requirements for the international hydrographic organization orders. Sensors [online]. 2019, 19, 3860 [accessed 2020-01-22]. eISSN 1424-8220. Available from: https://doi.org/10.3390/s19183860

[14] Federal radionavigation plan - Department of Defense. Department of Homeland Security, and Department of Transportation. [online] [accessed 2019-12-22]. 2017. Available from: https://www.navcen.uscg.gov/pdf/ FederalRadioNavigationPlan2017.pdf

[15] KRZYKOWSKA, K., KRZYKOWSKI, M. Forecasting parameters of satellite navigation signal through artificial neural networks for the purpose of civil aviation. International Journal of Aerospace Engineering [online]. 2019, 2019, 7632958 [accessed 2020-12-10]. ISSN 1687-5974. Available from: https://doi.org/10.1155/2019/7632958

[16] NIE, Z., ZHOU, P., LIU, F., WANG, Z., GAO, Y. Evaluation of orbit, clock and ionospheric corrections from five currently available SBAS L1 services: methodology and analysis. Remote Sensing [online]. 2019, 11(4), 411 [accessed 2020-01-05]. eISSN 2072-4292. Available from: https://doi.org/10.3390/rs11040411

[17] RTCA - Radio Technical Committee for Aeronautics. Minimum operational performance standards for airborne equipment using global positioning system/wide area augmentation system. Doc. DO-229D. RTCA, Inc. (RTCA). 2013.

[18] WALTER, T., BLANCH, J., ENGE, P. L5 Satellite based augmentation systems protection level equations. In: International Symposium on GPS/GNSS: proceedings. 2007.

[19] TIBERIUS, C., ODIJK, D. Does the HPL bound the HPE? In: NaviTec'08 workshop: proceedings. ESA-Estec. 2008.

[20] ICAO - International Civil Aviation Organization. Radio navigation aids. Standards and recommended practices (SARPS). 2014, Annex 10 Volume I.

[21] EGNOS Service Provider. Monthly performance report [online] [accessed 2020-03-10]. 2020. Available from: https://egnos-user-support.essp-sas.eu/new_egnos_ops/sites/default/files/documents/105\%20-\%20Monthly\%20 Performance\%20Report\%20-\%20January\%202020.pdf

[22] OCHIENG, W. Y., SAUER, K., WALSH, D., BRODIN, G., GRIFFIN, S., DENNEY, M. GPS integrity and potential impact on aviation safety. The Journal of Navigation. 2003 56(1), p. 51-65. ISSN 0373-4633.

[23] FELSKI, A., NOWAK, A., WOZNIAK, T. Accuracy and availability of EGNOS - results of observations. Artificial Satellites [online]. 2011, 46, p. 111-118 [accessed 2020-01-10]. ISSN 2083-6104, Available from: https://doi.org/10.2478/ v10018-012-0003-0

[24] FELSKI, A., NOWAK, A. On EGNOS monitoring in local conditions. artificial satellites [online]. 2013, 48(2), p. 85-92 [accessed 2020-01-10]. ISSN 2083-6104, Available from: https://doi.org/10.2478/arsa-2013-0007 
Annex

\begin{tabular}{ll}
\hline Abbreviation & Full name \\
\hline EGNOS & European Geostationary Navigation Overlay Service \\
SBAS & Satellite Based Augmentation Systems \\
GPS & Global Positioning System \\
RTCA & Radio Technical Commission for Aeronautics \\
GNSS & Global Navigation Satellite Systems \\
ESA & European Space Agency \\
OS & Open Service \\
SoL & Safety of Life \\
EDAS & EGNOS Data Access Service \\
ESR & EGNOS System Release \\
HPE & Horizontal Position Error \\
VPE & Vertical Position Error \\
HPL & Horizontal Protection Level \\
VPL & Vertical Protection Level \\
PL & Protection Level \\
NPA & Non-Precision Approach \\
APV-1 & Approach with Vertical Guidance \\
LPV-200 & Localizer Performance with Vertical Guidance \\
AL & Alarm Limits \\
SI & Safety Index \\
MI & Misleading Information \\
HMI & Hazardous Misleading Information \\
\hline
\end{tabular}

